\title{
Abortion, Termination of Pregnancy, or Unterbrechung? A Non-English-native Obstetrician's View on Obstetric English Terminology
}

\section{Abtreibung, Schwangerschaftsabbruch oder „Unterbrechung“? Ansichten eines nicht muttersprachlichen Facharztes für Geburts- hilfe zur englischen geburtshilflichen Terminologie}

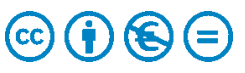

Author

Shigeki Matsubara

\begin{abstract}
Affiliation
Department of Obstetrics and Gynecology, Jichi Medical University, Tochigi, Japan

Key words

abortion, non-English native, termination of pregnancy, medical terminology

Schlüsselwörter

Abtreibung, Englisch nicht als Muttersprache, Schwangerschaftsabbruch, medizinische Terminologie
\end{abstract}

Bibliography

DOI https://doi.org/10.1055/a-0721-8418

Geburtsh Frauenheilk 2018; 78: 1217-1218 @ Georg Thieme

Verlag KG Stuttgart · New York | ISSN 0016-5751

Correspondence

Shigeki Matsubara, MD, PhD

Department of Obstetrics and Gynecology,

Jichi Medical University

3311-1 Yakushiji, Shimotsuke, Tochigi 329-0498, Japan

matsushi@jichi.ac.jp

\section{Dear Editor,}

Terminology is important in Obstetrics and Gynecology. For example, the International Federation of Gynecology and Obstetrics (FIGO) recently recommended the use of terminology of placenta accreta spectrum (PAS) disorders [1], which extinguishes the previous ambiguous terminology and makes research-data comparable. If the issue is genuinely scientific, problems rarely occur in defining medical terminology in English. In fact, myself, a non-native English obstetrician, participated in defining English terminology of PAS, together with native English specialists, E. Jauniaux from UK and R. M. Silver from USA [1].

However, things become different. I believe that Obstetrics and Gynecology is more likely to touch subtle issues. I find out a typical example indicative of a difficulty in expressing subtle obstetric issues in English. In the British Journal BJOG, two English native groups debated on the language of "abortion" and "termination of pregnancy" (TOP). Kavanagh and Aiken (UK and USA) [2] recommended nonuse of TOP:

1. TOP is less frequently used in the medical literature and by native English patients/society, and

2. TOP is not effective as a euphemism.
In contrast, Steer (UK) [3] recommended the use of TOP:

1. the word "abortion" is often used to express induced abortion (not spontaneous abortion), and

2. TOP definitely expresses induced abortion, reducing the ambiguity.

English-language-ambiguity and subtle issue (euphemism) aroused this debate, which was beyond scientific discussion.

The Japan Society of Obstetrics and Gynecology (JSOG) [4] defines abortion as pregnancy loss before 22 weeks of gestation, spontaneous or induced abortion. Although JSOG does not define TOP, our usage of TOP is, "a definite treatment of preeclampsia is TOP": definition of abortion and the usage of TOP roughly accords with those described in Williams Textbook [5]. Thus, although TOP may linguistically contain induced abortion, TOP is usually used for delivering a fetus after 22 weeks irrespective of mode of delivery mainly to save a mother's life and hopefully the fetus's life at the same time.

German is used among Japanese obstetricians [6]. Although German "Unterbrechung" linguistically means "termination", we use these two differently. Unterbrechung is identical to "künstliche Ausräumung" (induced abortion) whereas termination 
(TOP) indicates induced preterm delivery ( $\geq 22$ weeks), as described. Thus, spontaneous abortion, induced abortion (Unterbrechung), and TOP: there is no overlapping, misunderstanding, or ambiguity among Japanese obstetricians.

Thus, although no ambiguity exists in usage of abortion and TOP in Japanese obstetric practice, problems sometimes occur when we submit manuscripts to journals. Some journals recommend the use of miscarriage instead of spontaneous abortion. Some journals do not like the expression of TOP. Revision is sometimes asked only for this.

Online searches have reduced the handicap of non-English native doctors in obtaining the latest information. Without participating in international English-language meetings and without tremendous effort of grasping discussion fired off in rapid succession among English natives, non-natives fully understand the debate between Kavanagh and Steer. However, non-natives usually do not understand subtle nuances of English: for example, which expression is an euphemism. As such, non-natives still have a great handicap in reading and writing English, are obliged to be silent regarding English terms, and still are frequently blamed for using wrong English terminology.

Non-native doctors, as readers, reviewers, and writers, must obey the rules of terminology of English-language journals. I, a non-English native old obstetrician, ask native English scientists to settle the language issue, especially that associated with subtle nuances including euphemism.

\section{Conflict of Interest}

The authors declare that they have no conflict of interest.

\section{References}

[1] Jauniaux E, Silver RM, Matsubara S. The new world of placenta accreta spectrum disorders. Int J Gynaecol Obstet 2018; 140: 259-260

[2] Kavanagh Á, Aiken AR. The language of abortion: time to terminate TOP: FOR: Mandating TOP reduces research visibility and engenders stigma. BJOG 2018; 125: 1065-1065

[3] Steer PJ. The language of abortion: time to terminate TOP: AGAINST: 'Termination of pregnancy' is less likely than 'abortion' to be misunderstood or cause distress. BJOG 2018; 125: 1066-1066

[4] The Japan Society of Obstetrics and Gynecology. Glossary of Obstetrics and Gynecology (Japanese with English translation). Tokyo: Kanehara; 2008: $1-410$

[5] Cunningham FG, Leveno KJ, Bloom SL, Spong CY, Dashe JS, Hoffman BL, Casey BM, Sheffield JS. Williams Obstetrics. 24th ed. New York: McGrawHill; 2014

[6] Matsubara S. German words: still used by Japanese obstetrics and gynecology doctors. Arch Gynecol Obstet 2018; 297: 555-557 